\title{
A EDUCAÇÃO AMBIENTAL ENQUANTO UM DIREITO HUMANO E FUNDAMENTAL: uma análise da experiência constitucional brasileira ${ }^{1}$
}

\author{
Júlio César Madeira ${ }^{2}$ \\ Carlos Guilherme Madeira ${ }^{3}$ \\ Sérgio Danilo Madeira ${ }^{4}$
}

\begin{abstract}
RESUMO
O presente estudo, objetiva através de uma construção teórica e dogmática, reconhecer a educação ambiental estabelecida na CF de 88 , como um direito e garantia fundamental do cidadão brasileiro, posto que este reconhecimento não vem sendo conferido pela doutrina constitucional e ambiental que se ocupa do tema. Ademais, objetiva-se estabelecer o registro de que a educação ambiental contribui diretamente para a promoção e proteção da dignidade da pessoa humana, a qual na arquitetura normativa da constituição federal se revela como ponto central de fundamentação das demais normas e princípios jurídicos. Para a realização desse desiderato, recorre-se inicialmente a uma leitura dos direitos fundamentais, consubstanciada em uma interpretação que confira unidade a constituição em seu conteúdo material, bem como de que a leitura da educação ambiental sob o prisma dos direito humanos.
\end{abstract}

PALAVRAS-CHAVE: educação ambiental, direitos fundamentais, direitos humanos; dignidade da pessoa humana.

\section{INTRODUÇÃO}

Neste texto pretendemos examinar questões atinentes ao meio ambiente, sobretudo, ao direito ambiental o qual entendido nesse estudo como perfeitamente passível de ser concretizado em seu conteúdo material, através da efetividade da instituição pelo Poder Público da educação ambiental.

Buscamos assim, analisar o direito ambiental realizado em seu conteúdo através dos pilares da educação ambiental, inserindo-a na perspectiva dos direitos fundamentais previstos na CF de 88 bem, como na esteira dos direitos humanos reconhecidos pela comunidade internacional e registrados nos documentos oficiais que vinculam os Estados soberanos.

\footnotetext{
${ }^{1}$ Este texto é uma escrita parcial de pesquisa realizada no âmbito da pós-graduação.

2 Bacharel em Direito, Bacharel e Licenciado em Ciências Sociais, mestrando do Programa de Pósgraduação em Educação (PPGE/UFPel), bolsista CAPES, membro do Grupo de Pesquisa/CNPq Comunicação, Cultura, Tecnologias e Modos de Subjetivação, email: juliocesarmadeira@ gmail.com

3 Bacharel em Direito, mestrando do Programa de Pós-graduação em Ciências Sociais (ISP/UFPel), bolsista CAPES, email: guilhemadeira@gmail.com

${ }^{4}$ Bacharel em Direito pela Universidade Federal de Pelotas - UFPel. email: sdm.madeira@gmail.com
} 

constitucional e seu conteúdo com algo imprescindível para a concretização de uma cidadania ecológica.

Apresentar-se-á algumas considerações de como a norma em comento é vislumbrada no ordenamento jurídico brasileiro em termos de sua eficácia concreta no plano da vida. Tendo como ponto de partida o tema da eficácia das normas constitucionais, a educação ambiental estaria situada com base em uma visão clássica da hermenêutica constitucional, proposta por Silva (1998), como norma jurídica cuja natureza de seus efeitos se revelaria de forma limitada, não produzindo seus principais comandos jurídicos de forma direta e estariam seu principias resultados vinculados à atividade legislativa infraconstitucional.

Dessa forma, o conteúdo jurídico das normas de eficácia limitada, para este jurista, serviria precipuamente para atingir dois objetivos: a) o de estabelecer normas de princípio instituitivo (ou organizativo) $)^{5}$; b) estabelecer normas de princípio programático, “através das quais o constituinte, em vês de regular, direta $e$ imediatamente, determinados interesses, limitou-se a traçar-lhes os princípios para serem cumpridos pelos seus órgãos (legislativos, executivos, jurisdicionais $e$ administrativos), como programas das respectivas atividades, visando à realização dos fins sociais do Estado” (SILVA, 1998,p. 138).

Portanto, com base no exposto, percebemos que a educação ambiental se apresenta à luz de uma visão clássica das normas constitucionais no direito brasileiro, sob o estandarte de ser um projeto jurídico-político elaborado pelo legislador constituinte a ser consolidado no tempo, cujo dever de realização é atribuído ao Estado Brasileiro. Elemento que prejudica a urgência da questão ambiental nos contextos atuais na medida em que a coloca com algo a ser pensado e tutelado a posteriori; como algo que depende de lei definidora, e não de efetividade imediata, a partir do cidadão constranger judicialmente o Estado a promoção desse princípio.

\section{EDUCAÇÃO AMBIENTAL ENQUANTO DIREITO FUNDAMENTAL POR FORÇA DA LEITURA DOS DIREITOS FUNDAMENTAIS E DA INTERPRETAÇÃO CONSTITUCIONAL}

\footnotetext{
5 “São, pois, normas constitucionais de princípio institutivo aquelas através das quais o legislador constituinte traça esquemas gerais de estruturação e atribuições de órgãos, entidades ou institutos, para que o legislador ordinário os estruture em definitivo, mediante lei”. (SILVA, 1998, p..126)
} 
O constituinte de 1988, ao estabelecer como principio fundamental da República Federativa Brasileira, a promoção da dignidade da pessoa humana, cuidou não de uma dignidade humana universal como valor almejado pela sociedade brasileira e que deva ser construída, mas um paradigma que venha a efetivar a singularidade das pessoas em suas situações jurídicas existências e patrimoniais.

E nessa perspectiva, colaciona-se o prestigiado conceito, acerca da dignidade da pessoa humana, formulado por Sarlet (1998), o qual a delimita como sendo:

A qualidade intrínseca e distintiva reconhecida em cada ser humano que o faz merecedor do mesmo respeito e consideração por parte do Estado e da comunidade, implicando, nesse sentido, um complexo de direitos e deveres fundamentais que assegurem a pessoa tanto contra todo e qualquer ato de cunho degradante e desumano, como venham a lhe garantir as condições existenciais mínimas para uma vida saudável, além de propiciar e promover sua participação ativa e co-responsável nos destinos da própria existência e da vida em comunhão com os demais com os seres humanos, mediante o devido respeito aos demais seres que integram a rede da vida. ·. (SARLET, 2009, p. 67)

Com base na transcrição acima se percebe que a dignidade da pessoa humana, não perpassa apenas a exclusividade de uma dimensão ou de um ângulo biológico de sua incidência. A dignidade da pessoa humana como princípio matriz de todos os direitos fundamentais, coloca a pessoa humana em um patamar diferenciado no qual se encontrava no Estado liberal. Por conta disso, os princípios constitucionais têm por meta orientar a ordem jurídica para realização de valores da pessoa humana como titular de interesses existenciais e patrimoniais. Desse modo, a educação ambiental emerge enquanto um conteúdo constitucional, em que o Estado tem a obrigação de promover, buscando a efetivação dos pressupostos universais estabelecidos pelos direitos humanos em face do respeito a esse principio da dignidade da pessoa humana.

Diante da análise dos direitos inseridos na constituição, percebemos que os diretos atribuídos como de status fundamental, se colocam como direitos que objetivam a afirmação social de todos os cidadãos perante a estrutura estatal. (SARLET, 2008), sendo inclusive oponíveis nas relações jurídicas estabelecidas entre particulares em virtude da eficácia horizontal dos direitos fundamentais. 


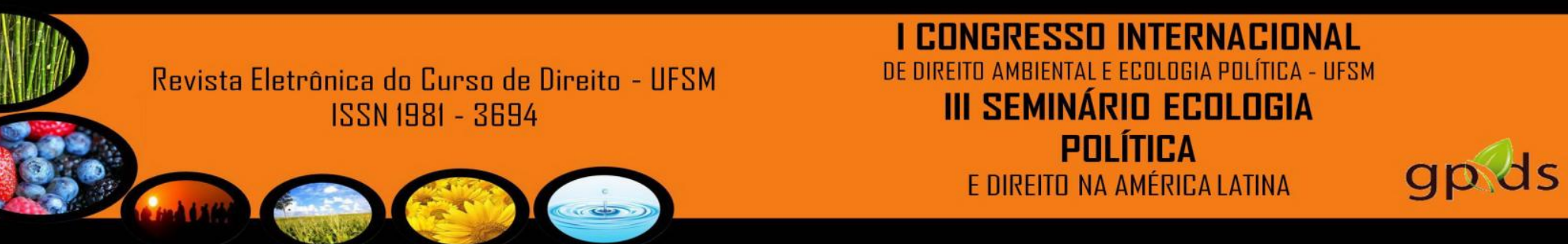

Nas linhas a seguir será elucidado o que concernem às diferentes gerações de direitos fundamentais construídas a partir da experiência constitucional e a satisfação de seu conteúdo cotejado com os pressupostos da educação ambiental.

\subsection{Classificações dos Direitos Fundamentais}

Para compreendermos um pouco mais acerca da educação ambiental como um direito fundamental presente em nossa carta constitucional, importante se faz examinala como um direito fundamental de caráter multidimensional, sendo analisadas as várias dimensões de incidência desse direito.

Para tanto, passaremos a analisar as referidas dimensões que a educação ambiental está inserida no ordenamento jurídico pátrio. Trata-se de quatros dimensões a serem analisadas. (SARLET, 1998)

\subsubsection{Primeira Dimensão de Direitos Fundamentais}

Observamos as discussões atinentes acerca da educação ambiental presente na primeira dimensão dos direitos fundamentais, pois ela representa instrumento que desperta a reflexão em relação às liberdades dos sujeitos no livre desenvolvimento de suas personalidades em um ambiente equilibrado e sadio, devendo tal proteção ser assegurada pelo Estado.

\subsubsection{Segunda Dimensão de Direitos Fundamentais}

Podemos perceber a educação ambiental no âmbito de sua inserção no cotidiano das pessoas, visualiza-se assim, sua vinculação com o a segunda ordem de direitos fundamentais, os quais versam acerca dos direitos mais especificamente vinculados aos âmbitos sociais, econômicos e culturais.

Dessa forma, a educação ambiental representa instrumento para problematizar a responsabilidade de toda a população, assim como do poder público para um novo horizonte, buscando a partir disso a construção de uma nova realidade socioambiental diante de inúmeras questões ambientais do contexto contemporâneo do Brasil.

\subsubsection{Terceira Dimensão de Direitos Fundamentais}


III SEMINÁRII ECOLOGIA

PDLÍTICA

Soma-se a essas análises a inclusão desses direitos relativos à educação ambiental, como pertencentes à terceira dimensão dos direitos fundamentais pelo caráter que ele se relaciona ao meio ambiente, tendo-se em vista a solidariedade com as gerações presentes $\mathrm{e}$ futuras em virtude da perspectiva modificadora que conscientização que a educação ambiental realiza nas mentalidades das pessoas, promovendo dessa maneira uma a nova consciência acerca da natureza.

\subsubsection{Quarta Dimensão de Direitos Fundamentais}

A quarta dimensão representa uma evolução em termos de direitos fundamentais, não tão consolidada pela ciência do direito, tendo-se em vista que esses direitos apresentam um caráter fundante, tendo conteúdo de outras dimensões de direitos fundamentais. Mas fundamentalmente, a educação ambiental localiza-se nessa quarta dimensão também pelo direito à informação que os sujeitos possuem acerca das questões socioambientais que estão à sua volta.

Diante disso, abaixo na figura 1, listamos uma relação dos direitos fundamentais, bem como a respectiva dimensão a que os mesmos estão relacionados:

\section{Figura 1- Dimensões dos Direitos Fundamentais}

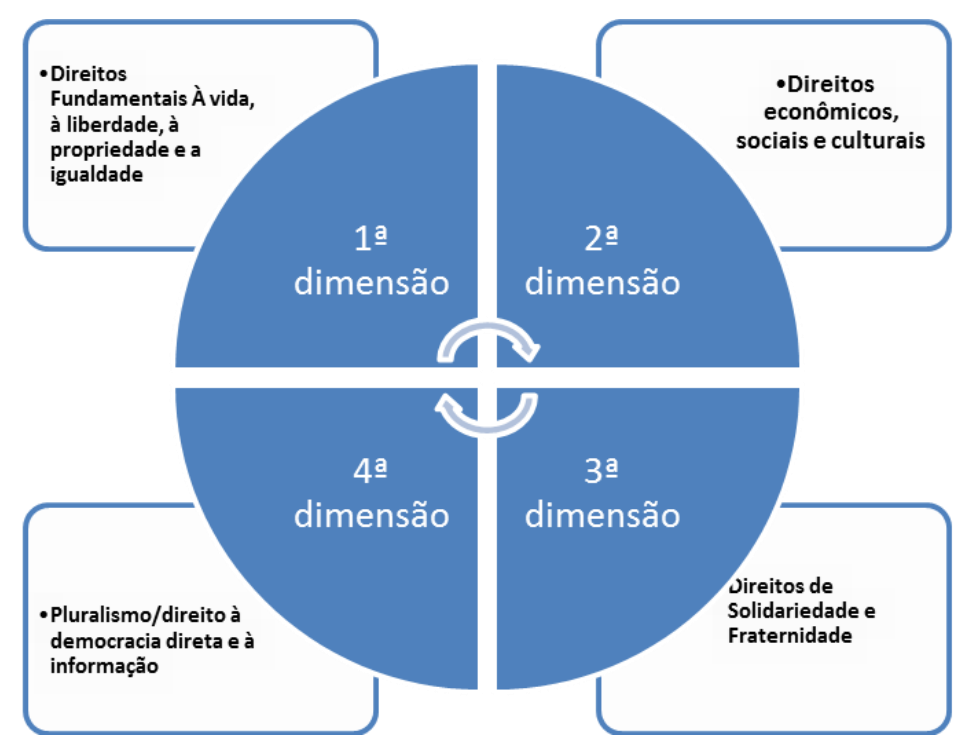

Fonte: Quadro Teórico elaborado por Júlio César Madeira, baseado na teoria de Sarlet (1998).

Diante da ilustração, podemos perceber a relação da educação ambiental com todas as dimensões de direitos fundamentais. Sendo visualizado no que concerne aos 
direitos de primeira geração acerca da liberdade tendo em vista a reflexão acerca da liberdade de cada sujeito em desenvolver-se em um meio ambiente saudável. Assim como, em relação à segunda dimensão tendo em vista a alteração que ela pode provocar no contexto socioambiental. Também na terceira geração pela solidariedade com as gerações futuras, assim como na quarta dimensão pensando a educação ambiental enquanto um instrumento problematizador e difusor das informações acerca das questões ambientais.

A partir da análise realizada da educação ambiental sob a égide dos direitos fundamentais no ordenamento jurídico brasileiro, devemos integrá-la sob a perspectiva daquilo que Canotilho (1993) denominou como Princípio da unidade da constituição, o qual propõe que a Constituição deve sempre ser interpretada em sua globalidade como um todo, obrigando o interprete a assim considerá-la e procurar harmonizar os espaços de tensão. Para tanto a seguir será realizado uma reflexão da educação ambiental como um direito fundamental, a partir dos pressupostos de interpretação constitucional.

Esta integração do conteúdo do direito ambiental a dos direitos fundamentais se justificaria, primeiramente, na medida em que ao adotarmos como parâmetros a perspectiva que segundo Sarlet (2009), existiria uma dimensão ecológica atinente a realização do conteúdo material do princípio da Dignidade da Pessoa. Ademais, que as gerações historicamente construídas em torno dos direitos fundamentais se encontrariam em seus contornos mais íntimos comprometidas com o direito ambiental. E por último que o Supremo Tribunal Federal, reconheceu que as normas definidoras de direitos e garantias fundamentais não se encontram enclausuradas nos contornos do artigo $5^{\circ}$, e por força de uma hermenêutica constitucional a educação ambiental seria passível de ser integrada ao rol dos direitos fundamentais.

\section{A EDUCAÇÃO AMBIENTAL COMO AFIRMAÇÃO DOS DIREITOS HUMANOS E SUA INCORPORAÇÃO AO ROL DOS DIREITOS FUNDAMENTAIS.}

O direito ambiental, concretizando através da vida sustentável e do meio ambiente ecologicamente equilibrado no plano internacional apresenta o aporte jurídico 
III SEMINÁRII ECDLOGIA

POLÍTICA

como inserto entre os direitos elencados na declaração Universal dos Direitos Humanos de 1948.

A Constituição Federal brasileira de 88 levando em conta o conteúdo atual de corpo normativo, não se apresenta como de estrutura fechada, tampouco taxativa. Pelo contrário apresenta uma estrutura semelhante à de um mosaico, principalmente, quando no seu artigo $5^{\circ}$, o qual versa sobre os direitos e garantias individuais, dispõe em seu parágrafo segundo que os direitos e garantias expressos nesta Constituição não excluem outros decorrentes do regime e dos princípios por ela adotados, ou dos tratados internacionais em que a República Federativa do Brasil seja parte.

Ademais, como fulcro na recente alteração no texto constitucional introduzida pela emenda constitucional de $\mathrm{n}^{\circ} 45$, a qual acrescentou ao artigo $5^{\circ}$ da $\mathrm{CF}$ o parágrafo terceiro que dispõe que os tratados e convenções internacionais sobre direitos humanos que forem aprovados, em cada Casa do Congresso Nacional, em dois turnos, por três quintos dos votos dos respectivos membros, serão equivalentes às emendas constitucionais, dando ensejo ao que atualmente se denomina dentre os constitucionalistas da existência de um bloco de constitucionalidade, amplia o conteúdo das normas constitucionais.

Dessa forma, os tratados de direitos humanos anteriores à emenda constitucional acima noticiada, atualmente são tratados como normas supralegais que se encontram acima das demais normas vigentes e apenas abaixo da Constituição, sendo a tese jurídica adotada pelo Supremo Tribunal Federal quanto ao tema. Atualmente, os tratados internacionais que versam sobre direitos humanos pactuados pelo Estado brasileiro, poderiam ser incorporados no ordenamento jurídico brasileiro de duas formas: a) através de sua incorporação pelo sistema de votação das emendas constitucionais, de modo a permitir a sua formal e material legitimidade de norma constitucional; b) independentemente de qualquer votação os tratados de direitos humanos assinados pelo Estado brasileiro teriam a força normativa de supra legalidade, pelo que seu valor jurídico só se subordinaria à Constituição.

Deste último entendimento discordamos, uma vez que todas as normas que versem sobre direitos humanos aderidas pelo Estado Brasileiro, já gozarão no plano interno da natureza material de direitos fundamentais, nada obstante o não preenchimento de requisitos formais e procedimentais. 



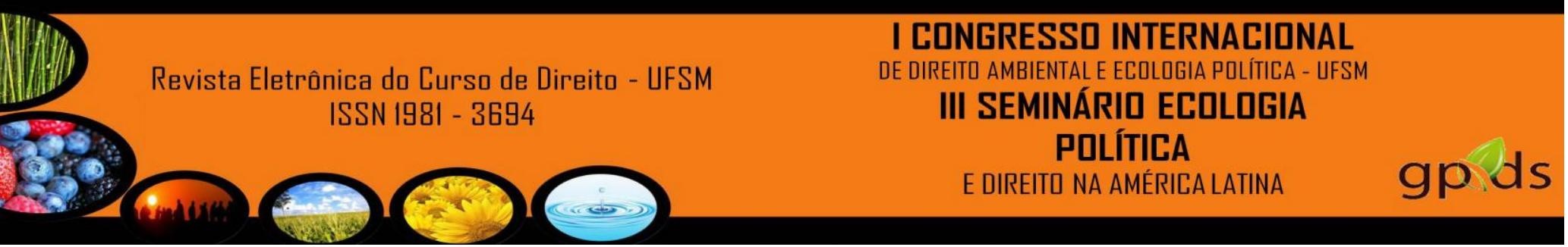

SARLET, Ingo Wolfgang. A Eficácia dos Direitos Fundamentais. Porto Alegre: Livraria do Advogado, 1998.

SARLET, Ingo Wolfgang. Dignidade da Pessoa Humana e Direitos Fundamentais na Constituição Federal de 1988. Porto Alegre: Livraria do Advogado, 2009.

CANOTILHO, José Joaquim Gomes. Direito Constitucional e Teoria Constitucional. Coimbra: Almedina, 1993.

SILVA, Jose Afonso da. Aplicabilidade das Normas Constitucionais. São Paulo:Malheiros, 1998. 